\title{
... der werfe den ersten Stein
}

Christian Marti

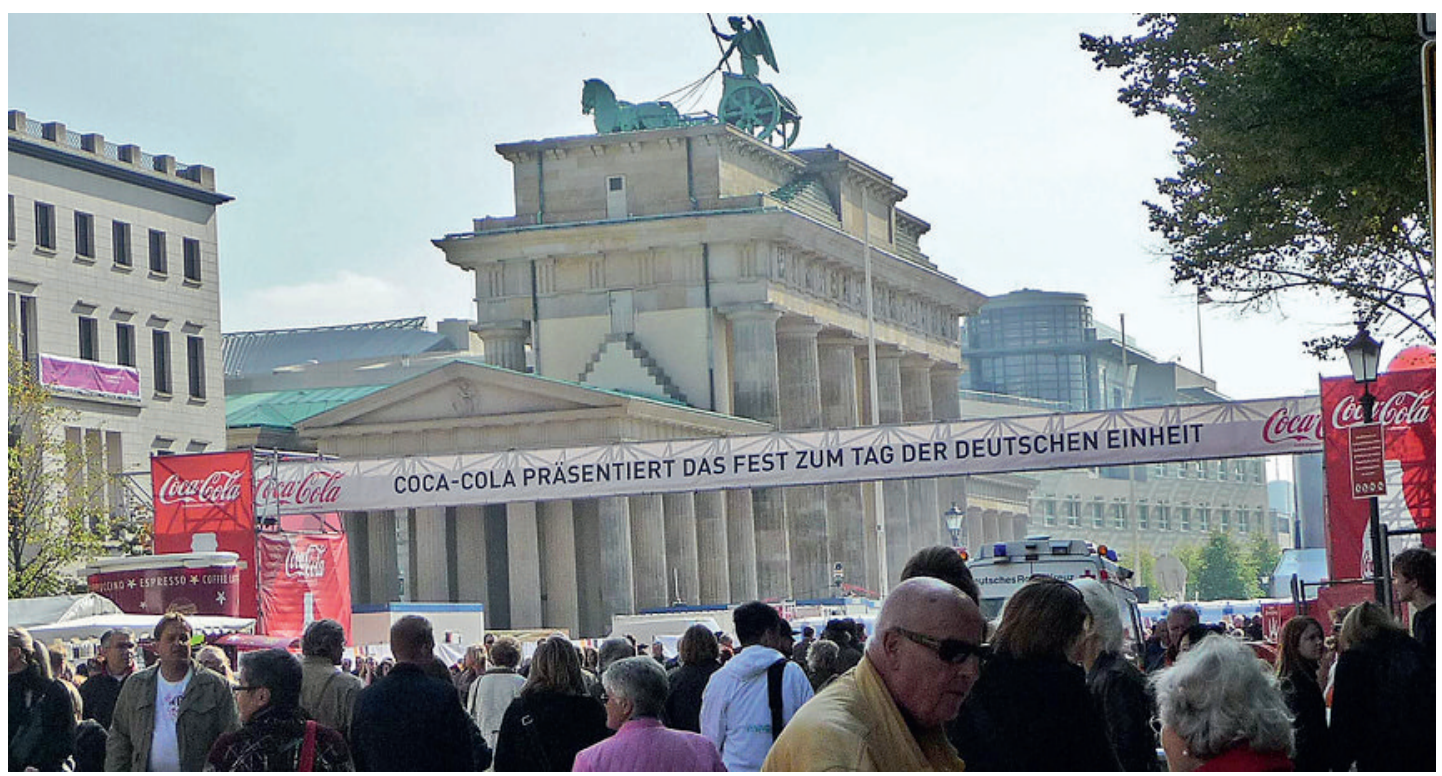

«Coca-Cola präsentiert das Fest zum Tag der deutschen Einheit.» Mit Spruchbändern dieses Inhaltes sei die Umgebung des Brandenburger Tors geradezu gespickt gewesen (s. Abb.). Dies erzählt mir - halb belustigt, halb verärgert oder entrüstet - ein scharfsinniger und geistreicher Kollege mit standespolitischen Meriten, der am Vortag vom diesjährigen Kongress der deutschsprachigen Onkologen und Hämatologen aus
Nun frage ich mich ernsthaft, was denn beunruhigender ist: die Firma Coca-Cola, die das Fest der deutschen Einheit in Berlin (mit-)finanziert oder die deutschsprachigen Onkologen und Hämatologen aus Deutschland, Österreich und der Schweiz, die sich ihren gemeinsamen Kongress in Berlin weitgehend von Big Pharma finanzieren lassen? Eines ist trotzdem klar: Während die Kongressteilnehmer einen eher

\section{Die Frage, ob denn der Kongress eventuell auch gesponsert wurde, fand der Kollege} dann allerdings gar nicht lustig und keiner Antwort wert.

Korrespondenz:

Dr. med. Christian Marti Rosinliweg 44 CH-8400 Winterthur

christian.marti@hin.ch
Berlin zurückgekehrt ist. Die Frage, ob denn der Kongress eventuell auch gesponsert wurde und wenn ja, von wem, fand der Kollege dann allerdings gar nicht lustig und keiner Antwort wert.

Darum habe ich die Homepage zur Kongressveranstaltung aufgesucht, deren Sponsorenliste sich wie ein Who is who von Big Pharma liest [1]. Weiter lese ich, dass im Rahmen des Kongresses vierundzwanzig Satellitensymposien [2] angeboten wurden, alle organisiert und wohl auch finanziert durch eine einzelne Pharmafirma - eine eher ungünstige Voraussetzung für eine nüchterne und kritische Selektion oder Würdigung der Beiträge. Weiter erfahre ich im Internet, dass die Pharmaindustrie 2009 mit 464 Millionen Franken (Fabrikabgabepreis) allein für Krebsmedikamente [3] in der Schweiz einen deutlich höheren Umsatz erzielte als Coca-Cola Schweiz mit 421 Millionen Franken [4]. symbolischen Unkostenbeitrag als Kongressgebühr entrichten, bezahlen die Teilnehmer am Fest zum Tag der deutschen Einheit mit Sicherheit den vollen Preis für jede Dose Coca-Cola.

\section{Literatur}

1 www.interplan.de/pages/dgho2010/front_content. php?idcat=319

2 www.interplan.de/pages/dgho2010/front_content. php?idcat=331

3 Interpharma: Pharmamarkt Schweiz (Ausgabe 2010) bzw. www.interpharma.ch/de/fakten-und-statistiken/ pharma-markt-schweiz/6575.asp?ShowBackButton=1

4 www.presseportal.ch/de/pm/100000818/100003810/ coca_cola_schweiz_gmbh 